\title{
Un Objeto Virtual de Aprendizaje (OVA) para el Movimiento Armónico Simple (M.A.S) y sus Aplicaciones
}

\section{A Virtual Learning Object (vlo) for the Simple Harmonious Movement and its Applications.}

\section{Virtuelles Lernobjekt für Die Einfache Harmonische Bewegung und seine Anwendungen}

Jaime Malqui Cabrera Medina. Magister en TIC en educación. Universidad Cooperativa de Colombia. Neiva. Colombia. jaime.cabrera@campusucc.edu.co

\begin{abstract}
Resumen
El presente artículo contempla los componentes pedagógicos, comunicativos, técnicos y de gestión, necesarios para el desarrollo de un Objeto Virtual de Aprendizaje (OVA) cuyo propósito es el de apoyar a profesores y estudiantes en el proceso de enseñanza aprendizaje en el aula o fuera de ella del movimiento armónico simple (M.A.S) y sus aplicaciones - Periodo de un péndulo simple y periodo de un oscilador armónico simple -, en el curso de Física de Ondas. El trabajo en el OVA se hizo atendiendo la metodología de los materiales educativos computarizados (MEC) que contempla las fases de análisis, diseño, desarrollo, evaluación e implantación. En las diferentes etapas se aplicaron instrumentos a estudiantes del cuarto semestre de ingeniería de sistemas curso física de ondas. Como resultado se obtuvo un Objeto Virtual de Aprendizaje (OVA) constituido por cinco Objetos de Aprendizaje a saber: cinemática, dinámica y comportamiento energético de un cuerpo que posee M.A.S, así como, periodo de un péndulo simple (leyes) y periodo de un oscilador armónico simple (leyes). Cada uno de los Objetos contempla, como mínimo: objetivos de aprendizaje, contenido informativo, actividades de aprendizaje, evaluación y metadatos, además de manual de usuario, créditos, autores, para saber más, recursos en la Web, otras tareas y saber más. Con la implementación del OVA se pretende fortalecer el momento de formación presencial y el de trabajo independiente.
\end{abstract}

Palabras claves: Movimiento armónico simple (M.A.S), estilos de aprendizaje, Objetos Virtuales de Aprendizaje (OVA), Materiales Educativos Computarizados (MEC), enseñanza - aprendizaje.

\begin{abstract}
This article provides teaching, communication, technical and management components necessary for the development of a Virtual Learning Object (OVA) whose purpose is to support teachers and students in the teaching - learning in the classroom or outside her simple harmonic motion (SHM) and its applications - a simple period period of a pendulum simple harmonic oscillator - in the course of Physics of Waves. Work in the OVA was attending the methodology of computerized educational materials (MEC) that includes the phases of analysis, design, development, evaluation and implementation. Instruments at different stages were applied to the fourth semester students of engineering physics course wave systems. Kinematics, dynamics and energy behavior of a body having MAS, as well as period of a simple pendulum (laws) and an oscillator period: results in a Virtual Learning Object (OVA) consists of five Learning Objects obtained ie simple harmonic (laws). Each of the objects at the least: learning objectives, information content, learning activities, assessment and metadata, plus user manual, credits , authors, for more information, web resources, other tasks and learn more. With the implementation of the OVA is to strengthen the time of classroom training and selfemployment.
\end{abstract}

Keywords: Simple Harmonic Motion (SHM), Virtual Learning Object (OVA), Computerized Educational Materials (MEC), Teaching - Learning. 


\section{Zusammenfassung}

Der vorliegende Artikel betrachtet die pädagogischen, kommunikativen, technischen und bedienerischen Komponenten, die für die Entwicklung eines virtuellen Lernobjekts wichtig sind, welches die Lehrer und Schüler, die im Klassenzimmer oder außerhalb dessen in einem Kurs zur Wellenphysik die einfache harmonische Bewegung und ihre Anwendungen, die Periodendauer eines Fadenpendels oder die Periodendauer eines einfachen harmonischen Oszillators, durchnehmen und diese im Unterricht unterstützen soll.

Die Arbeit am virtuellen Lernobjekt berücksichtigte die Methode der computerisierten Lehrmaterialien, welche die Phasen der Analyse, des Designs, der Entwicklung, der Bewertung und der Implantierung betrachtet. In den verschiedenen Etappen wurden Instrumente auf Studenten des vierten Semesters des Systemingenieurwesens im Fach Wellenphysik angewandt. Als Ergebnis erhielt man ein virtuelles Lernobjekt, welches aus fünf Lernobjekten bestand: Kinetik, Dynamik, Energieverhalten eines Objektes mit einer einfachen harmonischen Bewegung, sowie die Zeitspanne eines Fadenpendels (Gesetze) und die Zeitspanne eines einfachen harmonischen Oszillators (Gesetze). Jedes einzelne dieser Objekte betrachtet mindestens die folgenden Punkte: die Lernziele, den Informationsgehalt, die Lernaktivitäten, die Bewertung und die Metadaten, außerdem die Bedienungsanleitung, die Nachweise, die Autoren und, um mehr zu über das Thema zu erfahren, Weblinks usw. Mit der Einführung des virtuellen Lernobjekts wird versucht, gleichzeitig den Präsenzunterricht und auch die eigenständige Erarbeitung eines Themas zu fördern.

\section{Introducción}

En el proceso de enseñanza - aprendizaje implementado en el programa de Ingeniería de Sistemas de la Universidad Cooperativa de Colombia, sede Neiva, se detectan falencias reflejadas en falta de hábitos de estudio, hábitos de estudio próximos a las evaluaciones, falta de hábitos de trabajo en equipo, falta de hábitos para consultar en libros de texto, pobre habilidad para la comunicación oral con la lengua materna y el lenguaje científico, falta de comprensión, bajos resultados obtenidos en las pruebas Saber Pro y deserción continua de estudiantes a causa de la falta de dominio de conceptos básicos para entender las matemáticas y la física.

Los métodos y las estrategias que tiene el docente para la enseñanza de estas ciencias no se apartan del método tablero, marcador y exposiciones magistrales o aquel que ha sido tradicionalmente impartida por el paradigma de laboratorio - seminario - conferencia" y escasamente recurren a prácticas en el laboratorio, generando en los estudiantes ambientes discrepantes para motivar la comprensión de dichas ciencias.

Los procesos de enseñanza - aprendizaje - evaluación tradicionales se enfrentan a una evaluación por competencias (plan estratégico nacional - Naveguemos juntos - 2013 a 2022) ${ }^{1}$, implica el uso del contexto, las TIC y la actividad diaria, y la Metodología Interdisciplinaria Centrada en Equipos de Aprendizaje "MICEA (Mora 2005)" es el componente fundamental para el desarrollo de los cursos por competencias de la Universidad Cooperativa de Colombia, donde el profesor es un facilitador del aprendizaje.

Los métodos tradicionales de enseñanza - aprendizaje - evaluación generan un abismo de incomprensión que aleja al estudiante de los buenos resultados. Por tal razón, el propósito general de desarrollar un OVA para la enseñanza - aprendizaje del M.A.S y sus aplicaciones en el curso de Física de Ondas - que permita dinamizar el proceso de enseñanza aprendizaje basado en objetivos, contenidos y actividades como también un proceso de evaluación para fortalecer el aprendizaje presencial.

Con la intención de fortalecer el momento de formación presencial y el manejo del tiempo independiente, se hace una hipótesis en el sentido de que es posible considerar que los objetos virtuales permiten que el estudiante adquiera desempeños y competencias en el manejo de conceptos y aplicaciones del M.A.S en su lugar de trabajo, en su casa o en cualquier parte y a cualquier hora, hipótesis que tiene sentido en la definición de objeto de aprendizaje en la que afirma (Onrubia 2005) que un ova es cualquier entidad, digital o no digital, que puede ser usada, reusada o referenciada durante el aprendizaje apoyado por tecnología. Por tal razón, los objetos virtuales se constituyen en una herramienta de apoyo para encontrar canales que faciliten la interacción del mundo moderno con los conceptos de la física tradicional en el contexto de un aula de clase (Quiceno 2013).

Las OVA se originan en los años 80 en Japón, cuando los jóvenes animadores inician sus propias producciones freelance en empresas productoras de animación para la televisión, estas sin censura para expandirse en el mercado a sectores equivalentes a las producciones en formato de historietas impresas (manga), llegando a varios sectores a nivel mundial. (Lozada 2014). Las OVAs se enmarcan dentro de los propósitos de las herramientas TIC, las cuales están produciendo cambios en las metodologías de enseñanza y aprendizaje, en la forma en que los profesores y estudiantes se relacionan con el conocimiento, y la manera en que interactúan los agentes involucrados en el proceso educativo. El uso de las TIC en educación

1-http://ucc.edu.co/prensa/2014/SiteAssets/Paginas/nuestro-mapa-de-navegacion-ya-esta-listo/Plan\%20Estrat\%C3\%A9gico\%20Nacional-pdf 
ha permitido relevar propuestas metodológicas que pedagógicamente llevan años de desarrollo (Salvat 2002).

(Cook 2002) Señala que los ambientes constructivistas basados en la informática permiten oportunidades de apoyo por medio de las sesiones tutoriales; sin embargo, existen los micromundos informatizados que, aparentemente, hacen menos necesario ese apoyo (tutoría - asesoría), permitiendo al estudiante valerse por sí solo de manera que se vuelve más autónomo.

El increíble avance tecnológico de los últimos años ha permitido que los procesos de enseñanza sean llevados al mundo virtual logrando así diversificar los esquemas, introduciéndolos en un plano en el cual el estudiante no se debe desplazar a un centro especializado, porque desde la comodidad de su PC puede acceder a planes de educación tanto formal como no formal (Gutiérrez 2009).

La virtualidad resuelve muchos de los problemas que la educación tradicional no puede enfrentar con sus estrategias, ya que en los últimos años la educación ha utilizado la educación virtual como soporte específico y complementario, a través de plataformas virtuales que incluyen herramientas para facilitar el aprendizaje, la comunicación y la colaboración.

Cuando el estudiante se enfrenta a estas plataformas, en algunas ocasiones las encuentra áridas, luego se requiere mediante la construcción de los ovas, motivar en los estudiantes la navegación por plataformas institucionales o el internet, despertar el interés por adquirir nuevos conocimientos, y desarrollar una autoevaluación con retroalimentación que permita validar por parte del mismo estudiante su avance en el conocimiento y el manejo del tiempo libre.

Las estrategias pedagógicas deben guardar estrecha relación con el mundo de la informática y sus avances tecnológicos al servicio de la academia siendo el docente el principal actor para utilizar herramientas tecnológicas en sus procesos de formación para crear OVA y aplicarlas en sus procesos educativos con las TIC.

Es de resaltar la importancia de la OVAS como alternativa en la implementación de estrategias didácticas que sirven como herramientas para facilitar el aprendizaje del estudiante en este nuevo mundo globalizado.

\section{Fundamentación Teórica}

\section{Componentes pedagógicos}

Un Entorno Virtual de Aprendizaje (EVA) se define como una plataforma tecnológica que trata de reproducir las condiciones y los recursos educativos de una clase presencial, proporcionando a los profesores y estudiantes las facilidades para la comunicación y la interacción, y venciendo de esta manera la necesidad de coincidir temporal y geográficamente de los actores implicados en el proceso de enseñanza-aprendizaje (Dorado, 2006).

Para el diseño de un EVA, se requiere considerar una serie de aspectos: los espacios definidos, el acceso y su funcionalidad y la facilidad para su manejo técnico al realizar intervenciones, son aspectos esenciales.

Pérez (2004) señala que una plataforma de formación a distancia, en la perspectiva de la interacción y en el contexto de una comunidad de aprendizaje, debería ser ante todo, transparente, amigable, de fácil acceso y contar con los siguientes espacios:

- Comunicación pedagógica para las actividades de aprendizaje basadas en la interacción (foros, trabajo en grupo, wiki, etc.)

- Comunicación social para el intercambio de mensajes personales y grupales.

- Tutoría para la comunicación personal y grupal, asesorar el desarrollo de las actividades, evaluar, etc.

- Ayuda técnica para la solución a problemas técnicos u organizativos. (Quiroz 2011)

Es importante tomar como referencia el proyecto desarrollado por la Doctora Mónica Silva Quinceno cuyo objetivo principal fue el diseñar y desarrollar Material Educativo Computarizado basado en Objetos Virtuales de Aprendizaje -OVA que permita potenciar un proceso de formación virtual, en estudiantes de la Universidad Cooperativa de Colombia sede Villavicencio, para el curso de Física mecánica en el programa de Ingeniería de Sistemas.

\section{Componentes comunicativos}

En el entorno virtual de aprendizaje se evidencia el objeto aprendizaje (OA) conformado por cinco Objetos a saber: cinemática, dinámica, energía y aplicaciones del M.A.S el cual se elaboró haciendo uso de las herramientas que ofrece la Suite de Adobe CS6 y en especial el software Flash siendo esté el principal para crear animaciones interactivas con sus respectivos botones, hipervínculos, entre otros, así como un diseño amigable y apropiado para el trabajo que se está desarrollando que es de carácter educativo por naturaleza.

Las animaciones de los Objetos Virtuales de Aprendizaje se realizan en Flash y se toma como referencia elementos teóricos, gráficos, vídeos y simulaciones. Los botones e hipervínculos de los Ovas permiten una navegación libre, para llegar al menú principal de cada OVA con todas sus opciones visibles para que el usuario las utilice siempre.

Para el caso de los menús en los pantallazos existentes y la interacción de botones e hipervínculos en cada forma ofrecida por el formato Flash, permitiendo concentrar la atención del usuario; de igual forma las animaciones son parte de la estrategia cognoscitivista que ayuda al aprendizaje de los estudiantes. 
Durante este componente comunicativo será evidenciado que Flash permite al usuario entrenar su mente en la manipulación de símbolos y en la manera de codificarlos, simbolizarlos y decodificarlos, permitiendo su participación activa, interacción de forma frecuente entre el maestro y el estudiante, participación y colaboración en grupo y conexión con el mundo real.

\section{Componentes técnicos}

La teoría de Neil Fleming $(2001)^{2}$ y sus estilos de aprendizaje son propicios para adaptarlos a ambientes virtuales, ya que brindan estrategias que se fortalecen con el uso de TIC, tales como mapas mentales, gráficas, tablas para visuales, mapas conceptuales para lectores, videos para aurales y visuales, y laboratorios virtuales (applets) para kinestésicos.

De esta manera, y en concordancia con lo propuesto anteriormente, se hace necesario incorporar a los ambientes de aprendizaje generados por los ovas, los estilos de aprendizaje adecuados a los medios tecnológicos, de tal manera que la adquisición del conocimiento por parte de los estudiantes avance a la par con el desarrollo tecnológico.

Como resultado de este ejercicio se construyen marcos teóricos recurriendo a diferentes fuentes y autores registrados en comunidades virtuales, textos, libros y páginas web, entre otros.

\section{Metodología}

Para la elaboración del Ova seguimos la programación estructurada y legible propuesta por Galvis (González 2006) para el desarrollo de materiales educativos computarizados MEC, con el propósito de hacer un uso adecuado del material educativo cuando se requiera, y adecuarlo a la necesidad respectiva.

\section{Análisis}

El instrumento vark, con el que se busca identificar el estilo de aprendizaje, está basado en una encuesta que contiene un total de 16 preguntas, todas identificadas con acciones que permiten determinar en el estudiante un grado de inclinación hacia un determinado estilo de aprendizaje. El estudiante encuestado puede señalar más de una opción. Cada pregunta está construida de tal manera que los estilos -Visual, Aural, Lector y Kinestésico- aparecen de manera aleatoria. Por ejemplo, para la primera pregunta, 10 estudiantes indican su inclinación hacia lo visual, 17 hacia lo aural, 14 hacia lo lector, y 13 hacia lo kinestésico. La tabla 1 muestra los resultados encontrados en la aplicación de la encuesta vark a 20 estudiantes del programa de Ingeniería de Sistemas.

Tabla 1. Resultados observados en la prueba vark, al aplicar el instrumento vark a 20 estudiantes del programa de Ingeniería de Sistemas de la Universidad Cooperativa de Colombia, sede Neiva

\begin{tabular}{|l|l|l|l|l|}
\hline & V & A & R & K \\
\hline 1 & 10 & 17 & 14 & 13 \\
\hline 2 & 13 & 10 & 6 & 12 \\
\hline 3 & 8 & 8 & 12 & 14 \\
\hline 4 & 15 & 12 & 10 & 8 \\
\hline 5 & 18 & 15 & 11 & 12 \\
\hline 6 & 9 & 9 & 8 & 10 \\
\hline 7 & 14 & 7 & 9 & 6 \\
\hline 8 & 10 & 16 & 12 & 15 \\
\hline 9 & 15 & 12 & 15 & 8 \\
\hline 10 & 12 & 13 & 12 & 12 \\
\hline 11 & 17 & 6 & 10 & 11 \\
\hline 12 & 15 & 14 & 9 & 16 \\
\hline 13 & 16 & 17 & 5 & 10 \\
\hline 14 & 12 & 12 & 15 & 6 \\
\hline 15 & 10 & 9 & 12 & 9 \\
\hline 16 & 8 & 8 & 10 & 13 \\
\hline 17 & 9 & 12 & 7 & 12 \\
\hline 18 & 14 & 15 & 9 & 6 \\
\hline 19 & 6 & 8 & 15 & 15 \\
\hline 20 & 16 & 12 & 6 & 10 \\
\hline
\end{tabular}

Fuente: Autoría propia

Tabla 2. Estadígrafos calculados en Excel que permiten identificar estilos de aprendizaje en los estudiantes de Ingeniería de Sistemas de la Universidad Cooperativa de Colombia, sede Neiva.

\begin{tabular}{|l|l|l|l|l|}
\hline & V & A & R & K \\
\hline Promedio & 12 & 12 & 10 & 11 \\
\hline error típico & 0,76908122 & 0,75569285 & 0,68579704 & 0,68435517 \\
\hline Mediana & 13 & 12 & 10 & 12 \\
\hline desviación estándar & 3,43779305 & 3,37794706 & 3,06551275 & 3,05906763 \\
\hline Varianza & 11,8184211 & 11,4105263 & 9,39736842 & 9,35789474 \\
\hline $\begin{array}{l}\text { Nivel de confianza } \\
(95 \%)\end{array}$ & 1,60893667 & 1,58092789 & 1,43470413 & 1,43168772 \\
\hline
\end{tabular}

Fuente: Autoría propia

2 - http://www.vark-learn.com/english/page.asp?p=questionnaire 
Los resultados observados en la tabla 2 , muestran que el nivel de confianza de la prueba corresponde a un $95 \%$, valor que garantiza la estabilidad y credibilidad de los datos: el mayor valor esperado, representado por los promedios, está ubicado en los componentes Visual (v) y Aural (a); el menor coeficiente de variación indica que el promedio más estable y menos disperso es el estilo de aprendizaje Kinestésico (k), el aprendizaje visual (v) es cercano al Aural (a), y el estilo kinestésico $(k)$ se acerca al aprendizaje Lector $(r)$.

\section{Figura 1. Pantalla principal OVA}

\section{OVAS: Objetos Virtuales de Aprendizaje} Movimiento Armónico Simple y Aplicaciones

OVA cinemática

OVA dinámica

OVA energía

OVA péndulo simple

OVA oscilador armónico simple

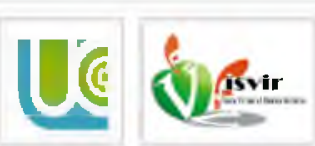

Redes sociales:

\section{f}

\section{Diseño}

La observación de estos resultados permite identificar una muestra multimodal, con preferencia de estilos de aprendizaje hacia lo visual y aural y con menos inclinación hacia los estilos de aprendizaje lector y kinestésico sin alto grado de diferencia, resultados que permitieron desde el análisis de estadígrafos llegar a esta aseveración.

Esta conclusión permitió construir una aplicación de tipo multimodal en la que se aprecia el aspecto visual y aural en la construcción y estructuración de la navegación en el OVA (Figura 1).
El proyecto Objetos Virtuales de Aprendizaje OVAs - Movimiento Armónico Simple V Aplicaciones permite realizar un estudio cualitativo por parte de docentes y estudiantes del comportamiento cinemático, dinámico y energético de un objeto que se mueve de manera armónica y simple, así como estudiar cualitativa y cuantitativamente las leyes que rigen: el periodo de un péndulo simple y el periodo de un oscilador armónico simple o sistema masa resorte.

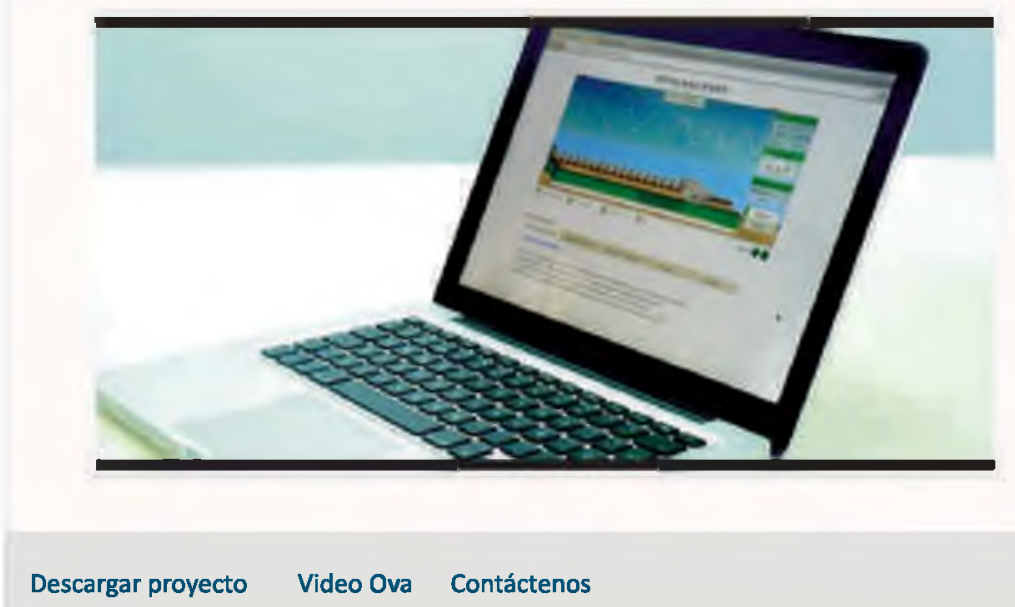

Universidad Cooperativa de Colombia - Neiva - Semillero de investigación Fisvir - Copyright @ 2013 Fisvir - Todos los derechos reservados Fuente: Autoría propia

Figura 2. Diseño menú de navegación

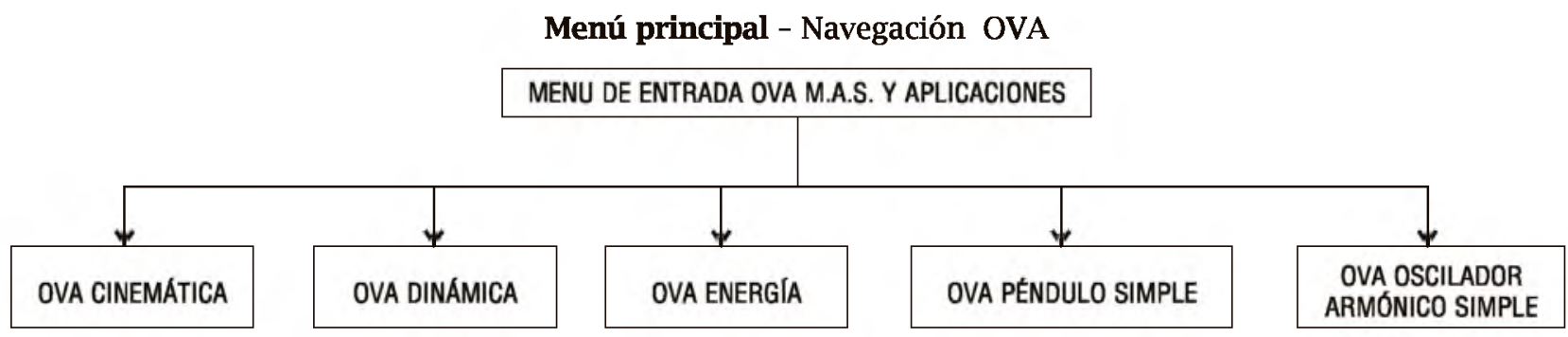

Fuente: Autoría propia 
Figura 3. Diseño menú de navegación OVA tema de estudio

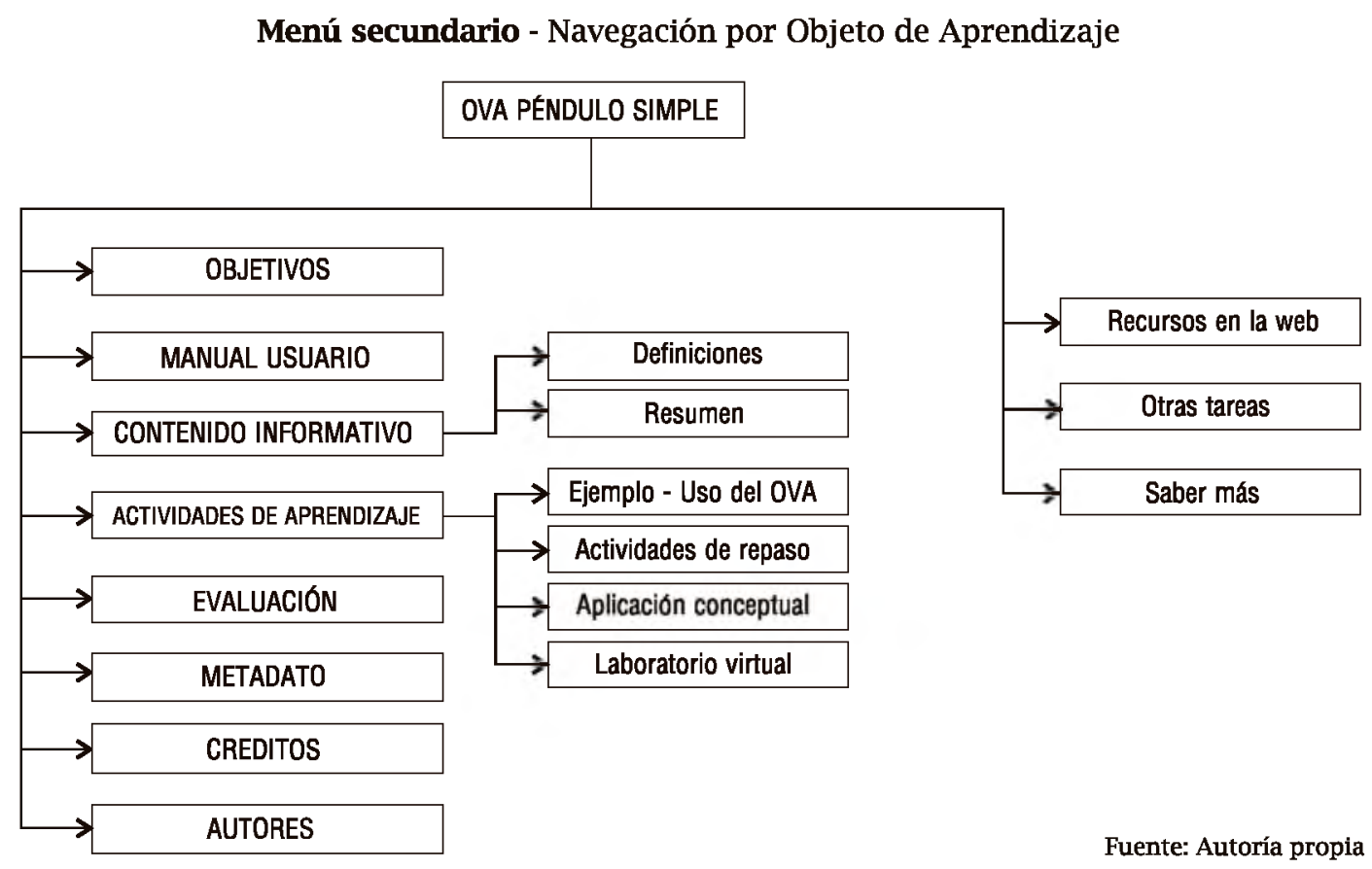

Para el diseño computacional se acude a las necesidades educativas, se establecen las funciones que se desea que sean cumplidas en el OVA, con el apoyo de sus usuarios, el profesor y los estudiantes. El hecho de presentar en un solo pantallazo de visualización el menú principal, permite al usuario libertad de navegación y libertad para abandonar el software cuando lo considere necesario (Figura 2 y 3 ).

Haciendo correspondencia al estilo multimodal identificado, el estilo de aprendizaje visual esta beneficiado en los videos tutoriales explicativos de manual de usuario para cada OVA como parte de las diferentes temáticas de aprendizaje (Figura 4 y 5 ).

\section{Video Tutorial pantalla inicial.}

\section{Figura 4. Presentaciones ova Física Mecánica}

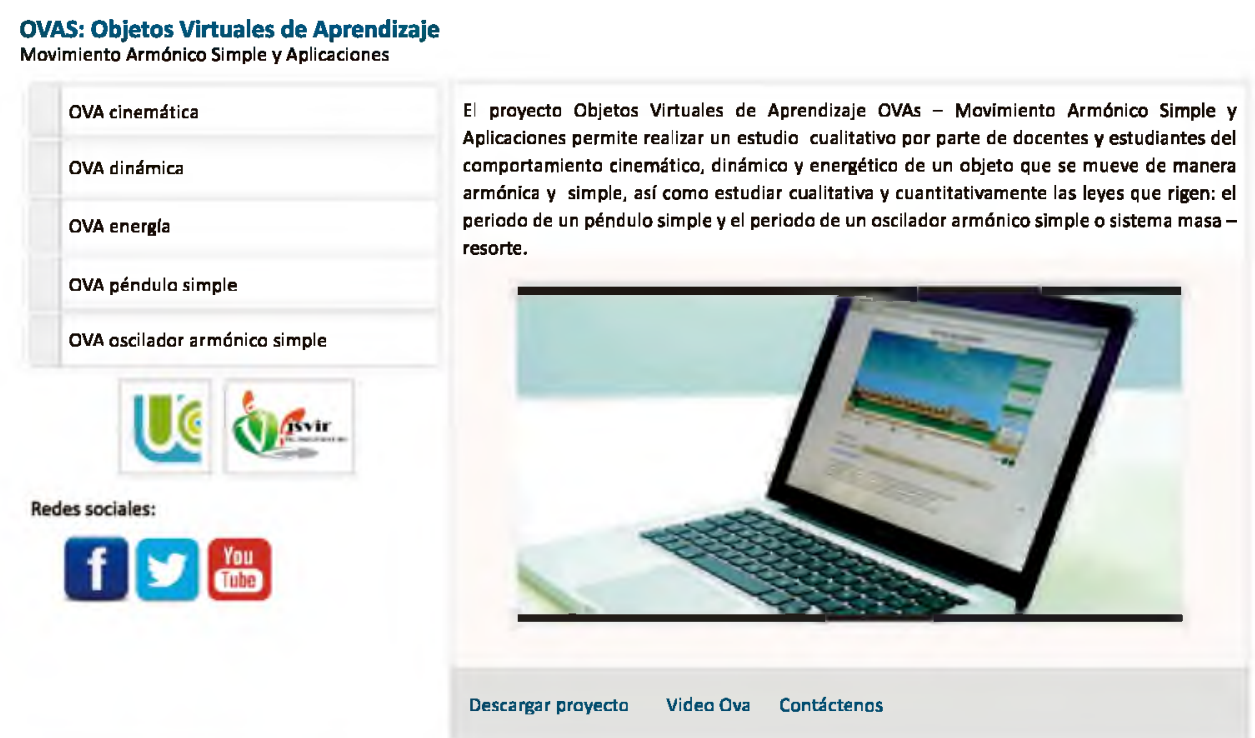


OVAS: Objetos Virtuales de Aprendizaje Movimiento Armónico Simple y Aplicaciones

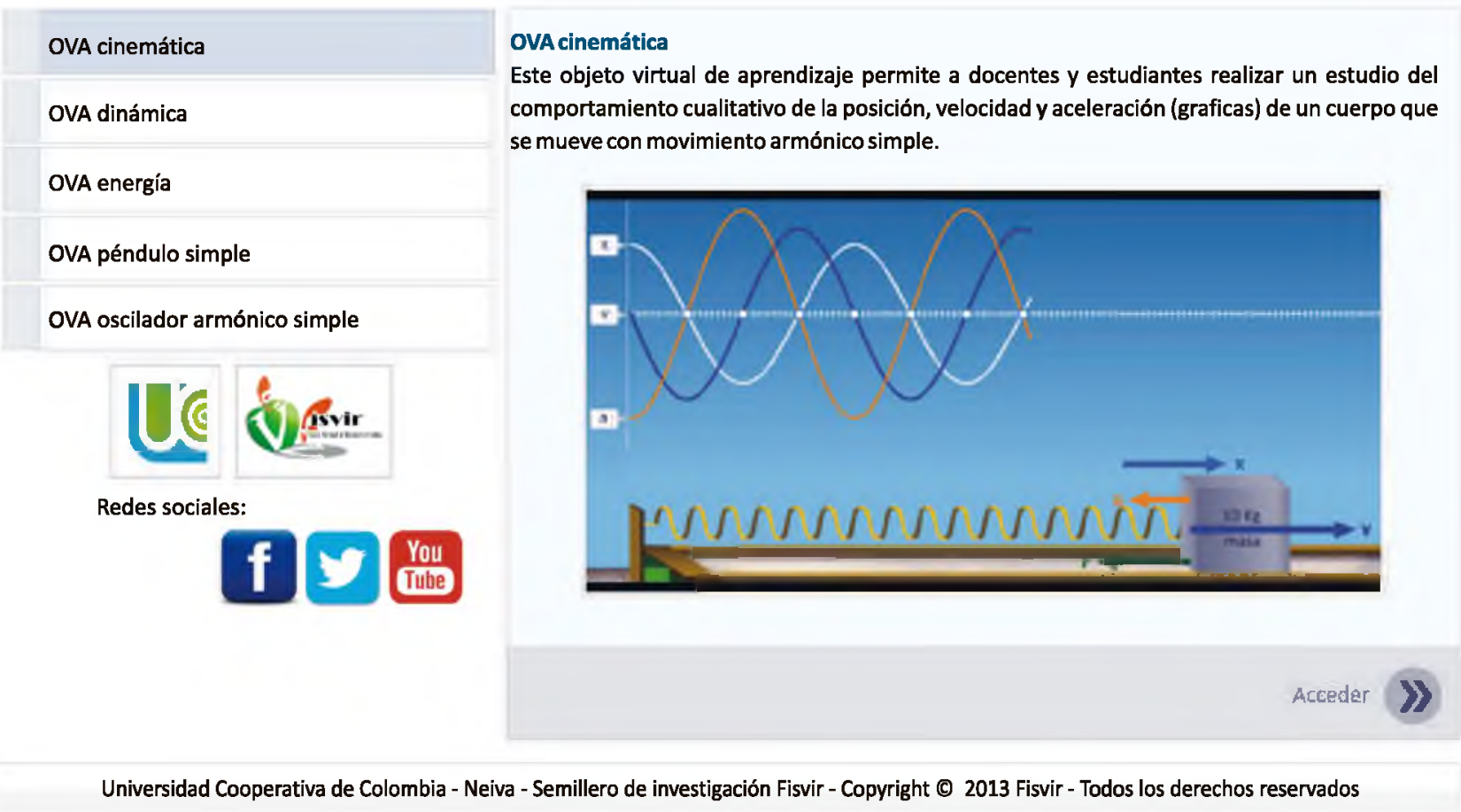

Fuente: Autoría propia

\section{Video Tutorial Pantalla OVA contenido}

Figura 5. Video de introducción a la ova Física Mecánica
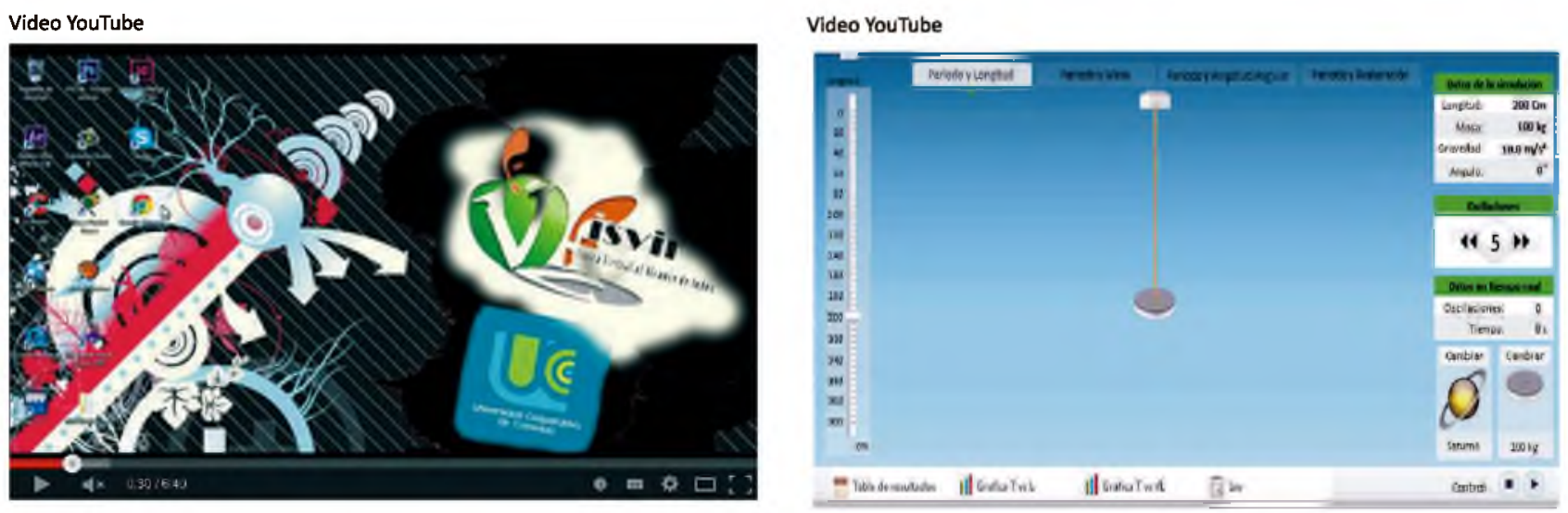

Fuente: Autoría propia

Las figuras 6 y 7 demuestra cómo se beneficia el estilo de aprendizaje kinestésico por cuanto implica una exploración con la pantalla para poder reconocer diferentes conceptos y poder tomar medidas de variables involucradas en un laboratorio virtual, como el mostrado en el ejemplo relacionado con cinemática de un M.A.S. 
Figura 6. Presentación conceptos cinemática de un M.A.S.

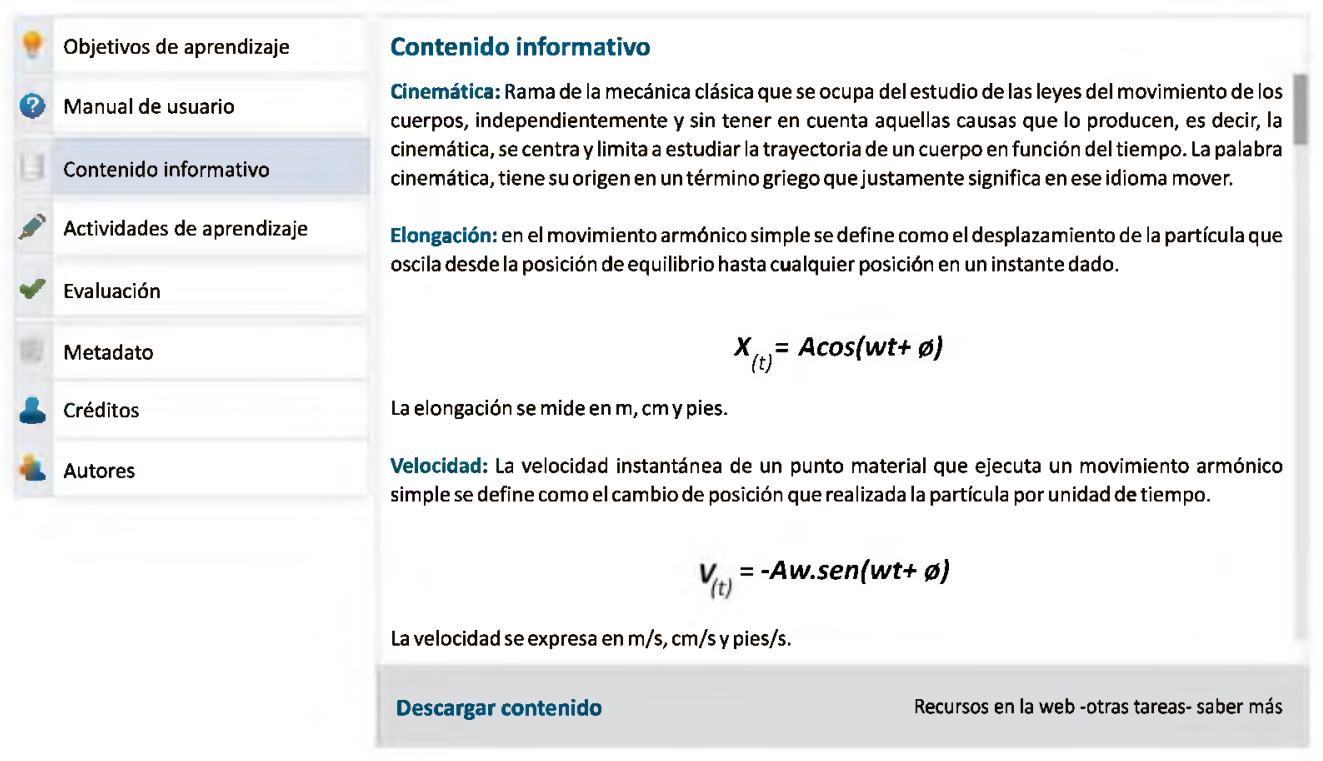

Fuente: Autoría propia

Figura 7. Presentación laboratorio virtual leyes de un péndulo simple.

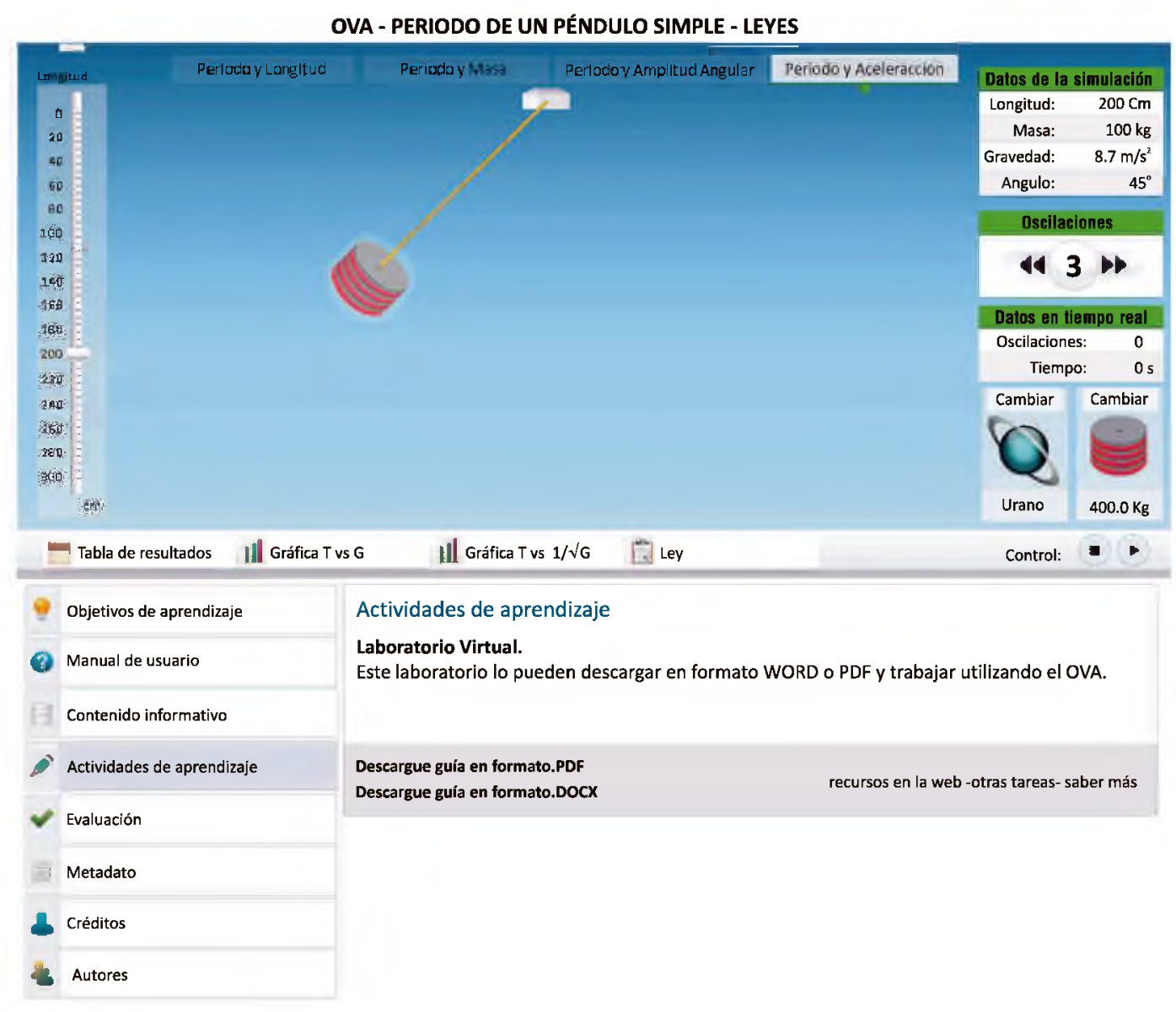

Fuente: Autoría propia 
El estilo de aprendizaje lector se evidencia cuando el estudiante se enfrenta al reto de probarse, mediante el desarrollo y entrenamiento de una prueba estilo Saber Pro (figura 8).

Figura 8. Presentación de evaluación - Examen preguntas Saber Pro

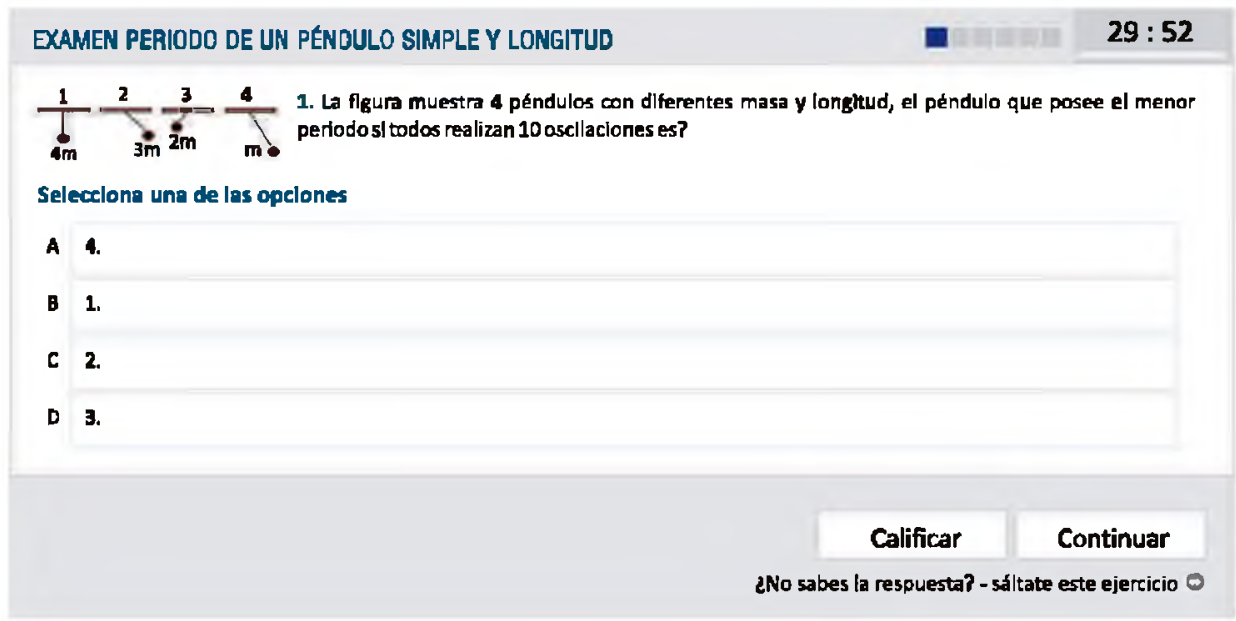

\section{Fuente:Autoria propia}

El menú principal del OVA ofrece cinco botones de navegación relacionados con los cinco OVAs que lo compone. El acceso a cualquiera de las OVAs se realiza haciendo clic sobre el nombre del OVA a estudiar, una vez ingrese el estudiante en la parte superior visualizara la animación y en la parte inferior izquierda de la pantalla un menú de acceso a los contenidos del OVA, que al dar un clic evidencia luego a su derecha el contenido deseado por el usuario. (Figura 9).

Figura 9. Vista inicial del OVA-Período de un péndulo simple-Leyes

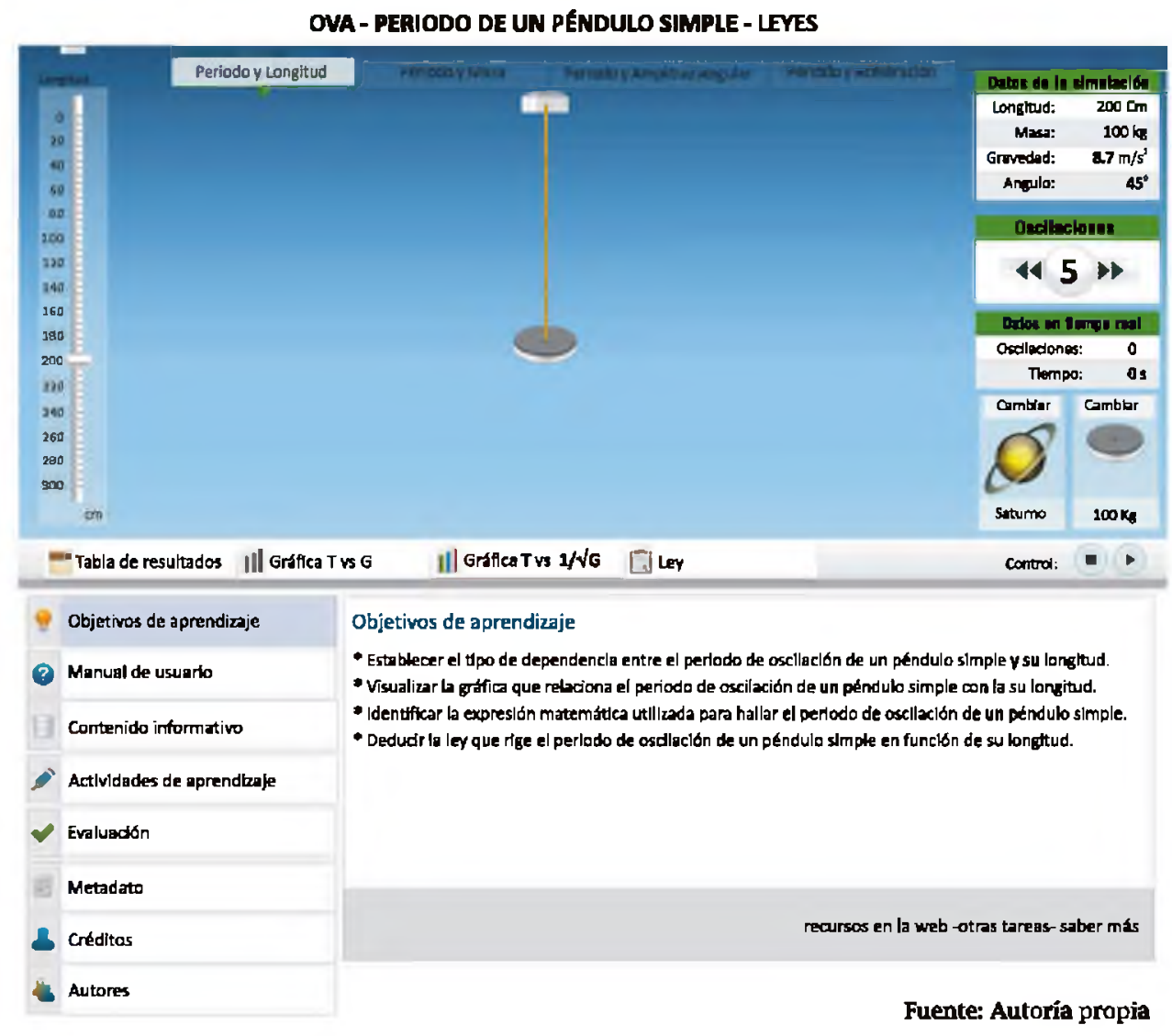




\section{Resultados}

Una vez identificados y adquiridos los diferentes conocimientos por medio de las diferentes estrategias de visualización: observación de imágenes y gráficas, videos, lectura e interacción (kinestésico), se tiene libre acceso a la evaluación y autoevaluación de cada unidad de aprendizaje (Figura 10).

Figura 10. Presentación acceso a la evaluación.

\begin{tabular}{|l|l|}
\hline Objetivos de aprendizaje & $\begin{array}{l}\text { Evaluación } \\
\text { Para presentar la evaluación da clic en el enlace. }\end{array}$ \\
\hline Manual de usuario & Contenido informativo \\
\hline Actividades de aprendizaje & Comenzar evaluación \\
\hline Evaluación & Metadato \\
\hline Créditos & \\
\hline
\end{tabular}

Los estándares de Drupal y los de la Suite de Adobe CS6 establecieron reglas técnicas para el diseño del ambiente virtual de aprendizaje y micromundo del OVA. Las herramientas utilizadas para el diseño y desarrollo del ova fueron Drupal, Flash, Camtasia, Adobe Premier, Adobe Photoshop, After effects, Adobe Audition, en su versión estudio permitieron el diseño de pantallas, botones, videos, textos, imágenes. (Figura 11).

Figura 11. Herramientas usadas para el desarrollo OVA

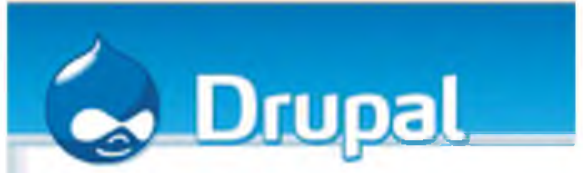

Fuente: elaboración propia
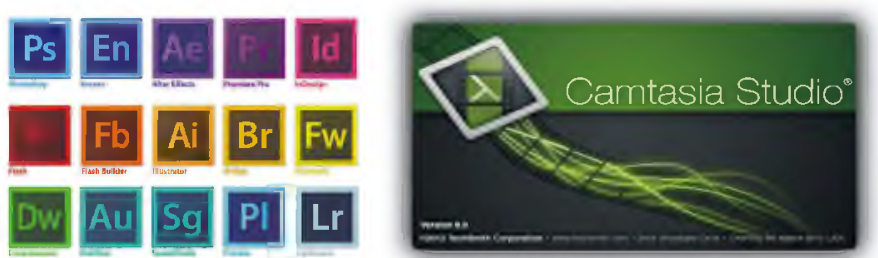

La evaluación se evidencia en pantallazos que permiten la navegabilidad entre las diferentes preguntas tipo saber pro, donde su enunciado, contexto y opciones de respuesta, pueden contener gráficos, textos y/o imágenes. El botón "Calificar", visible en la parte inferior de la pantalla, permite al usuario calificar su respuesta, y el botón "Continuar" permite la navegabilidad en el examen. La opción ¿no sabes la respuesta? Sáltate este ejercicio le permite al usuario pasar a la siguiente pregunta. (Figura 12).

Figura 12. Formato de Evaluación

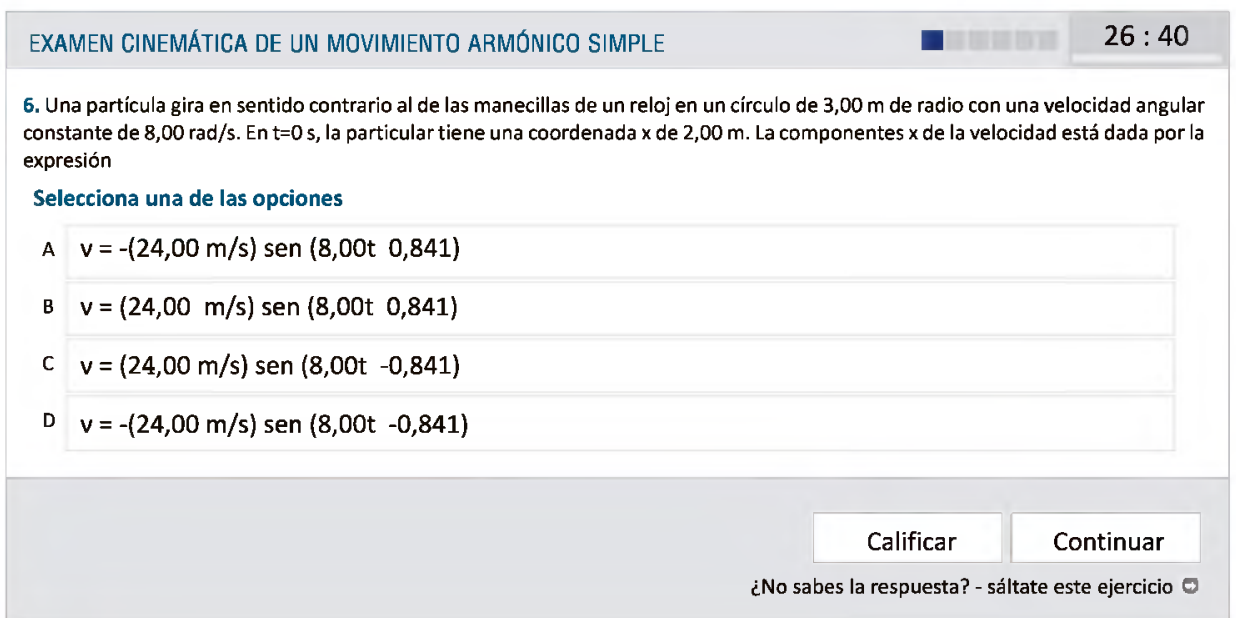




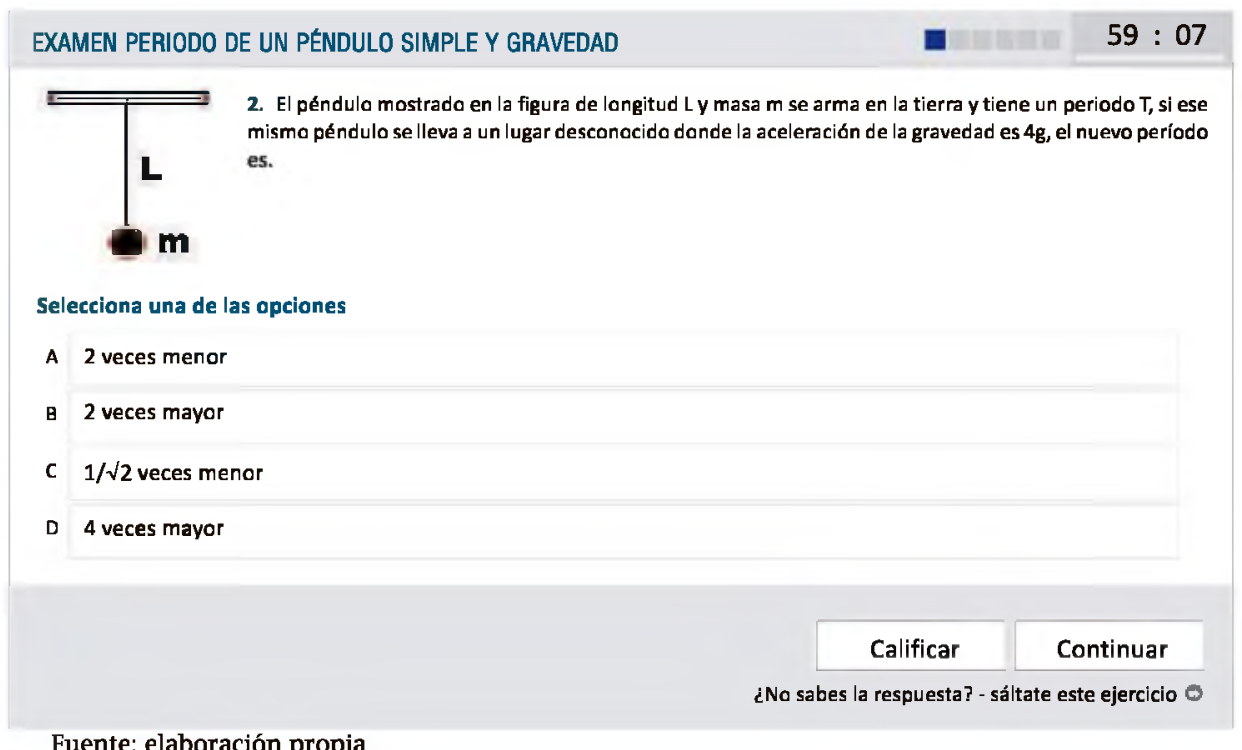

El hecho de que el estudiante realice un trabajo de autoevaluación, lo lleva a mejorar en el manejo de los conceptos básicos del movimiento armónico simple y sus aplicaciones, a la vez que toma conciencia del proceso autónomo que tiene dentro del aprendizaje.

La evaluación y las imágenes que contienen son libres para el estudiante y se convierten en un estímulo para el aprendizaje. La evaluación estilo prueba Saber Pro, ofrece un espacio de entrenamiento para este tipo de preguntas en la prueba de Estado. Las imágenes permiten recrear la imaginación y desarrollar competencias apropiadas, además de que están acordes a los estilos de aprendizaje identificados en el diagnóstico realizado al inicio del proyecto.

La evaluación inicia con una prueba piloto, realizada por una muestra representativa de los estudiantes del curso Física de Ondas, para quienes se hizo la evaluación formativa.

Se establecen las condiciones de los participantes, para que estos puedan cumplir los requisitos en condiciones normales; estudiantes del curso de Física de Ondas a la que corresponde el Ambiente Virtual de Aprendizaje, que posean los requisitos y la motivación. Para lograr las condiciones normales, la prueba debe hacerse bajo circunstancias lo más cercanas a las del uso del material: en el momento de estudio debido, y con los recursos y limitaciones del OVA. Para obtener una muestra representativa conviene hacer selección de individuos al azar entre la población objeto.

Se diseñaron pruebas sencillas de rendimiento como listas de observación y cotejo, para determinar cuánto aprendieron los usuarios; la efectividad del ambiente educativo se evalúa con los demás elementos. Las pruebas se aplicaran al menos al inicio y al final del uso del material para contrastar las diferencias. Es importante, además, de las pruebas de rendimiento para ver los propósitos del curso y los logros de los estudiantes de Física de Ondas en la unidad M.A.S, registrar cuanto tiempo se interactuó tanto con el material como con las ayudas externas del material que se requirió, así se sabrá que ganancia se obtuvo y las condiciones que la hicieron posible. Como complemento, es importante conocer la opinión de los usuarios sobre recurso virtual.

\section{Conclusiones}

El propósito de diseñar un Objeto virtual de Aprendizaje (OVA) para desarrollar la temática del M.A.S para los estudiantes de Ingeniería de Sistemas, lleva implícitamente a la tarea de implementarlo, lo cual permitirá fortalecer el momento de formación presencial y el trabajo independiente. La seguridad de dicha aseveración proviene del hecho de que el OVA fue diseñado siguiendo propósitos pedagógicos fundamentados en estrategias de aprendizaje debidamente valoradas, y en metodologías de diseño y construcción apropiadas, de tal manera que el OVA cumpla con su objetivo de formación.

El ova de M.A.S y sus aplicaciones cumple con todos los elementos que debe tener una herramienta como esta: propone cinco temáticas de aprendizaje y en cada una de ellas objetivos, contenidos informativos, actividades de aprendizaje, evaluación y metadato.

Se logró identificar los componentes pedagógicos, comunicativos, técnicos y de gestión necesarios para el desarrollo del Objeto Virtual de Aprendizaje (OVA) que contempla la temática del M.A.S y sus aplicaciones. Cada uno de ellos está comprendido en el desarrollo de las etapas de la metodología MEC (figura 13). 
Figura 13. Componentes del mec

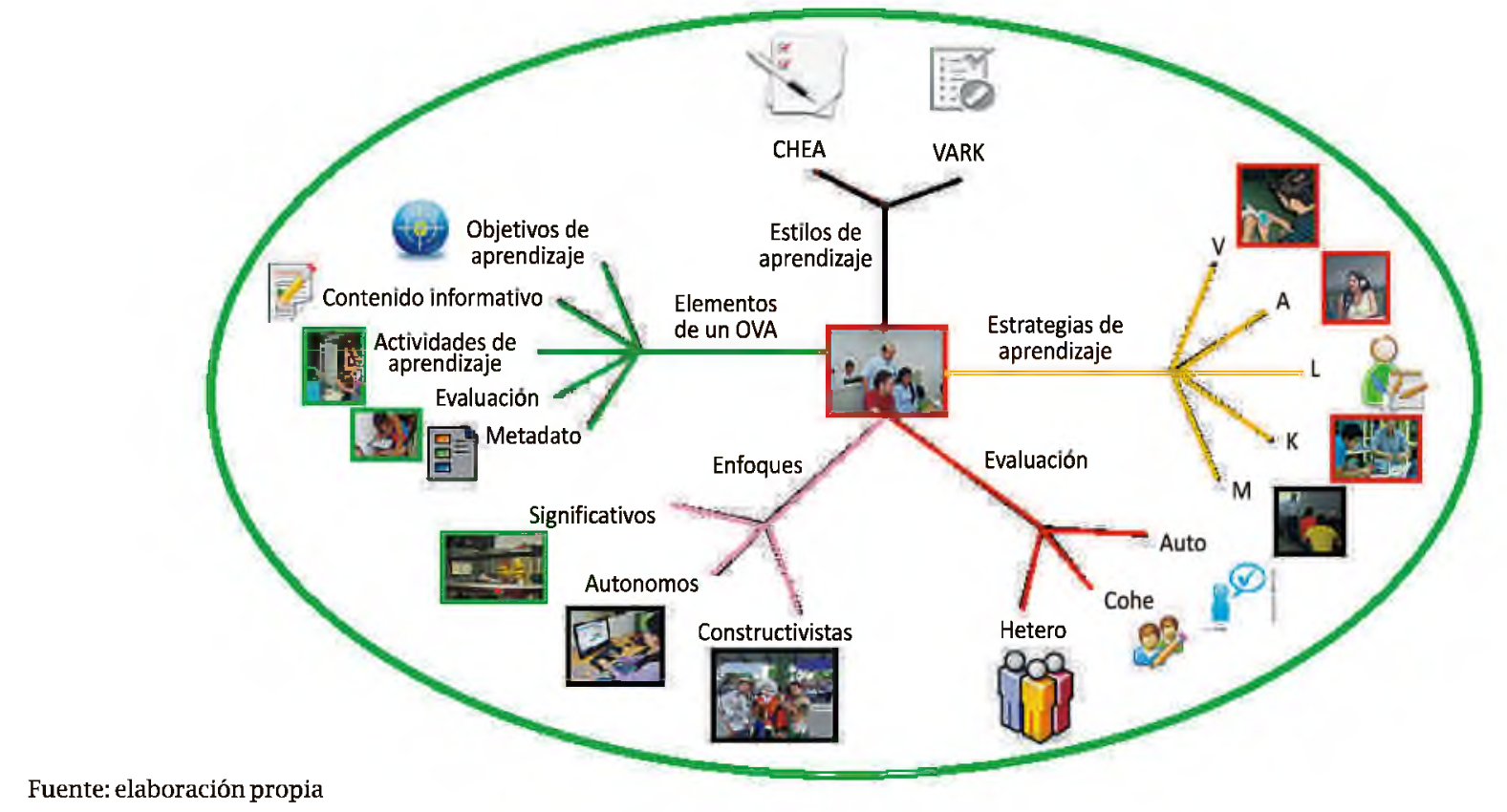

Mediante la aplicación del instrumento vark se identificaron los estilos de aprendizaje (Visual, Aural, Lector y Kinestésico). En el análisis de resultados de la encuesta se determinó que los estudiantes del curso de Física de Ondas del programa de Ingeniería de Sistemas de la Universidad Cooperativa de Colombia, son multimodales. Esta conclusión llevo a identificar las estrategias de aprendizaje que motivaron las evaluaciones, las autoevaluaciones, los enfoques pedagógicos y los elementos que debe contemplar el OVA.

La identificación del estilo multimodal en la muestra indicada, llevo a la utilización de clic de videos, sonidos, gráficos, tablas, pantallazos de textos, simulaciones, laboratorios virtuales, pruebas tipo saber pro, preguntas abiertas, como estrategias de aprendizaje en el desarrollo de la OVA de M.A.S y sus aplicaciones.

Figura 14. Componentes comunicativos

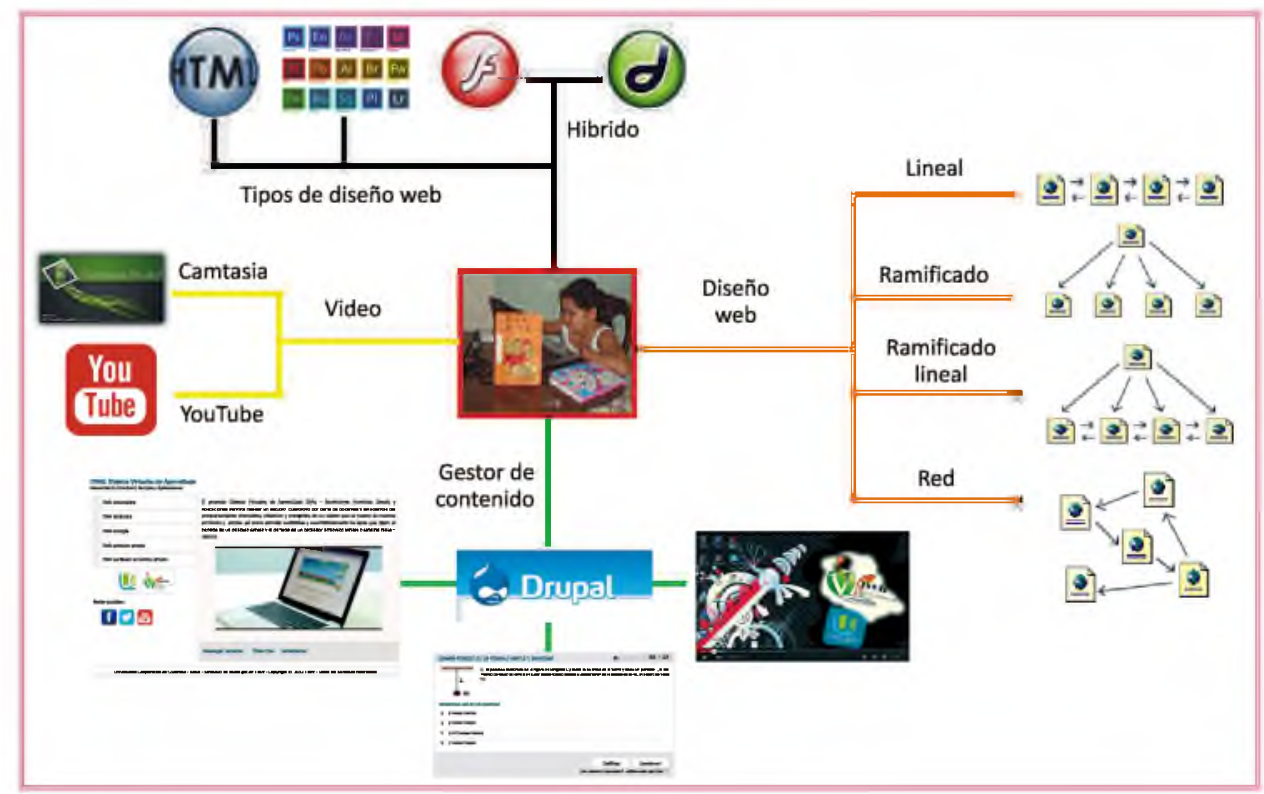

Fuente: elaboración propia 
Los componentes comunicativos (figura 14) en el desarrollo del OVA, fueron alcanzados mediante la utilización de la Suite de Adobe CS6 y en especial del software Flash, el cual muestra menús y submenús sin tener que abandonar el micromundo propuesto en el programa.

Cuando fue necesario navegar entre los subpantallazos internos del menú, además de los botones e hipervínculos realizados en Flash, se tuvieron en cuenta estilos de diseño para páginas web, como el diseño jerárquico y en cascada. Algunas aplicaciones gratuitas, y otras adquiridas, como el Camtasia, permitieron la edición y construcción de videos.

Los componentes técnicos y de gestión, se referenciaron por medio del uso de internet, de páginas web, del manejo de software para el diseño de gráficos, de programas de diseño para videos y espacios especiales para digitación y arreglo de sonidos, además de equipos con sistema operativo Microsoft Windows xp (figura 15).

Se desarrollaron mecanismos de evaluación y autoevaluación (actividades de aprendizaje) útiles para la supervisión y calificación del estudiante, propios de los Objetos Virtuales de Aprendizaje (OVA).

Los mecanismos de evaluación se construyeron teniendo en cuenta pautas dadas en la construcción de preguntas estilo Saber Pro, que permiten entrenar a los estudiantes para la presentación de pruebas nacionales en el área específica de Física de Ondas en la temática M.A.S y sus aplicaciones.

Para los mecanismos de autoevaluación se diseñaron formatos que se ajustan a los parámetros propuestos en las estructuras curriculares de la universidad, que contienen indicaciones que permiten medir el grado de aprendizaje alcanzado por cada estudiante en el desarrollo de cada unidad de aprendizaje (figura 16).

En ocasiones, el desarrollo de la temática del M.A.S y sus aplicaciones resulta complejo para la comprensión de los estudiantes. Los métodos de enseñanza virtual muestran buenos resultados en la medida en que existan estrategias apropiadas para este tipo de enseñanza. Los OVAs brindan herramientas de aprendizaje que ayudan en muchos aspectos a la comprensión de los temas; por tanto, se sugiere continuar con la construcción de OVA en los diferentes cursos, procurando seguir la misma metodología implementada en el desarrollo del OVA que se presenta para el desarrollo del M.A.S y sus aplicaciones.

Los OVAs brindan facilidad para ser archivados y reutilizados, se recomienda crear un banco de OVAs que contenga los metadatos de los Objetos Virtuales de Aprendizaje, con el fin de unificar los contenidos que se brinden semestre a semestre a los estudiantes en la sede Neiva y puedan ser utilizados en las otras sedes de la Universidad a nivel nacional. Adicionalmente este banco de datos deberá tener la opción de actualización.

Figura 15. Componentes técnicos y de gestión

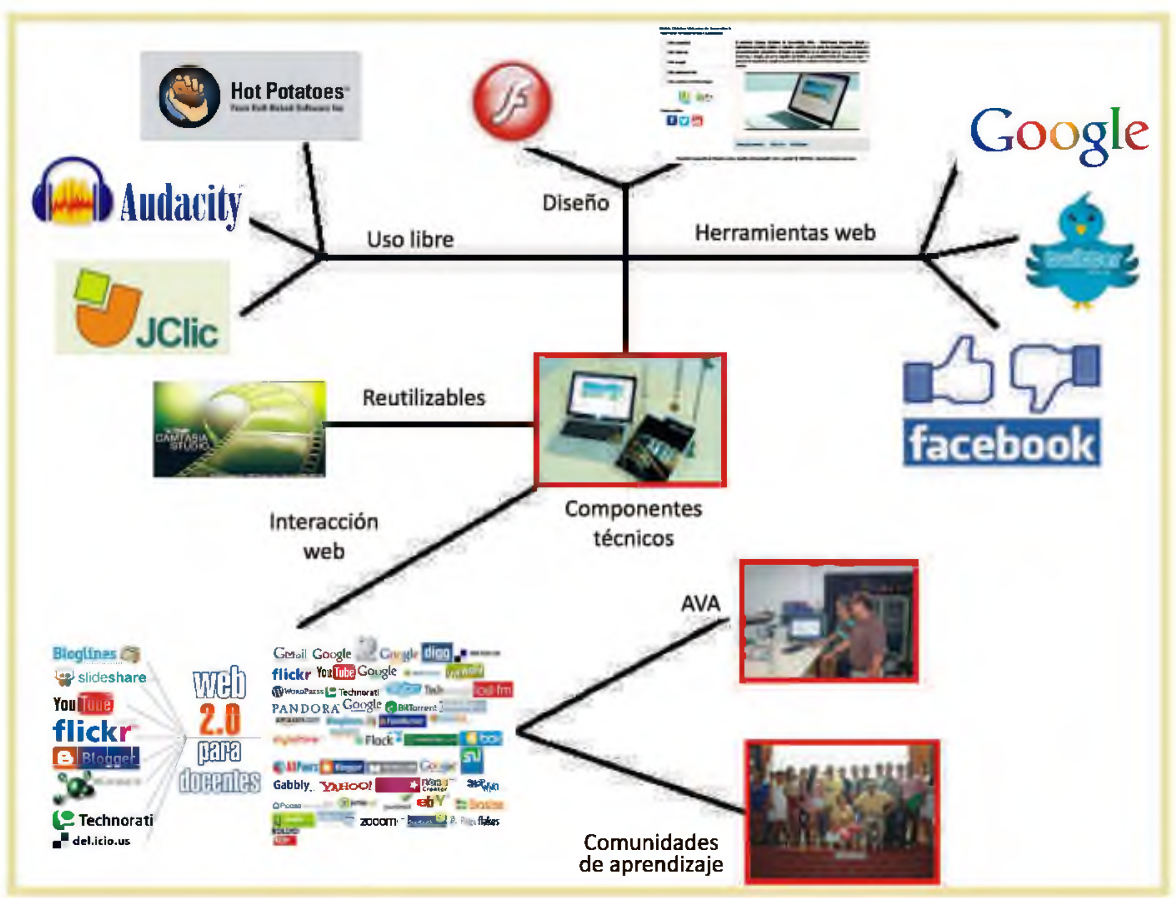

Fuente: elaboración propia 
Figura 16. Mecanismos autoevaluación

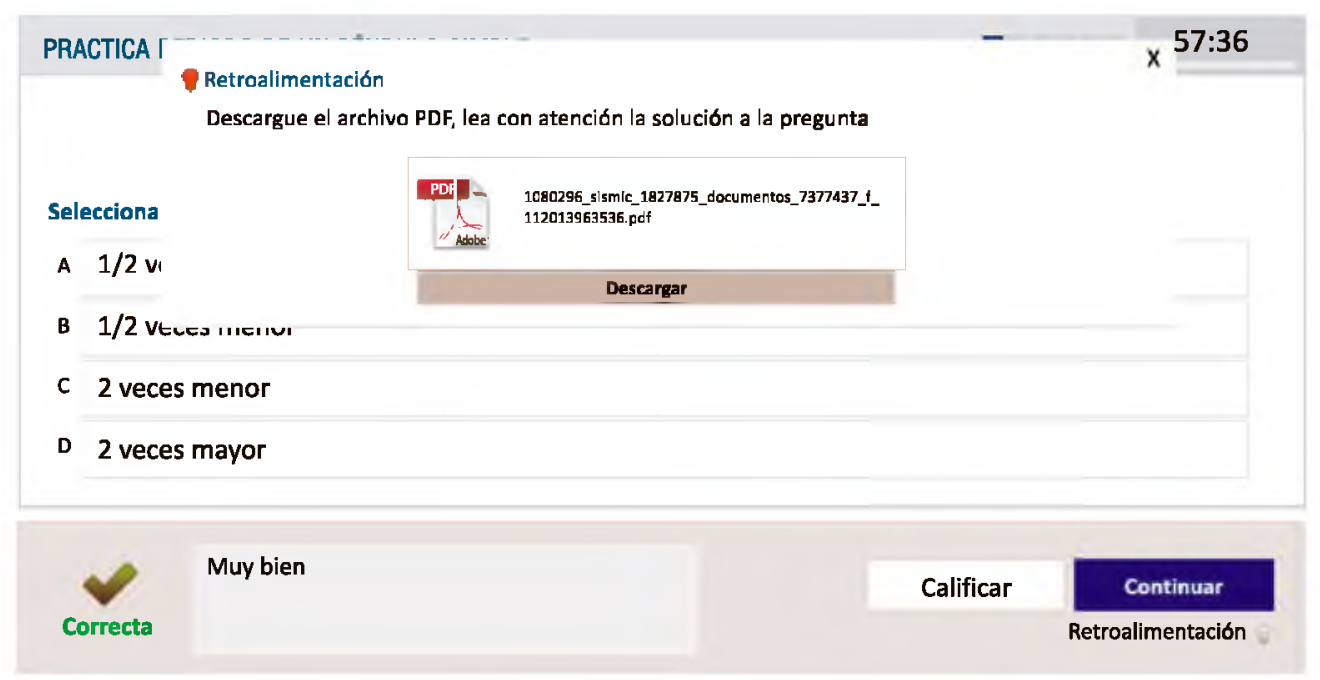

Fuente: elaboración propia

Los OVAs proponen un ambiente que permite motivar y emocionarse con el conocimiento, por lo que se recomienda que, mediante instrumentos, se verifique el grado de aceptación, aprendizaje y reconocimiento de estas herramientas. La idea es medir el grado de aprendizaje y establecer comparaciones entre la educación tradicional y la propuesta virtual de formación mediante OVA.

\section{Recomendaciones}

La validación de los Objetos Virtuales de Aprendizaje (OVA) permitirá medir su funcionalidad, por tanto, es menester que los docentes se apropien de estas herramientas y fortalezcan las debilidades que se tienen en el proceso de formación virtual. Las OVAs cumplen con su labor en la medida de su utilidad y su reutilización en diferentes contextos.

La creación de bancos de OVAs ya es una meta del Ministerio de Educación Nacional y de diferentes universidades del país, incluso de otros países. Asimismo, la inclusión de los desarrollos de OVAs en las líneas de investigación propuestas por el Comité Nacional para el Desarrollo de la Investigación (CONADI) de la Universidad Cooperativa de Colombia debellevar a este propósito.

El docente debe dedicar mayor tiempo y esfuerzo para preparar, actualizar y generar materiales educativos (Marques, 2000), pero no se puede convertir en dependiente de este tipo de materiales, a tal punto de que el hecho de no contar con un computador en una sesión de clase le impida desarrollar las actividades de aprendizaje.

Las instituciones deben brindar más apoyo a los docentes en la realización de este tipo me materiales educativos. Un estudio realizado por la Universidad de los Andes (Montoya y Cifuentes, 2007), muestra que, comparados con otros países de América Latina, en Colombia aún falta un mayor desarrollo en el tema, por tanto hay un gran campo de acción en la producción de materiales que debe ser atacado.

Finalmente, la metodología de desarrollo y construcción del presente trabajo debe ser motivo de validación, complementación de diferentes investigadores, lo que llevara a tener metodologías apropiadas y propias de la Universidad para el diseño de otras en diferentes asignaturas del currículo de los diferentes programas.

\section{Referencias Bibliográficas}

Cifuentes, G. y Montoya, D. (2007). Repensar la evaluación del aprendizaje: las tic en la educación superior. Recuperado de http://pensandoeducacion.uniandes.edu.co/ponencias/ Cifuentes\&Montoya-TIC_Evaluacion_aprendizaje.pdf

Cook, J. (2002). The role of dialogue in computer-based learning and observing learning: An evolutionary approach to theory. Recuperado de:

http://www-jime.open.ac.uk/jime/article/download/2002-5/88

Cook, John. "The role of dialogue in computer-based learning and observing learning: an evolutionary approach to theory." Journal of Interactive Media in Education, 2002: 29.

Del Moral, M. y Cernea, D. (2007). Diseñando Objetos de Aprendizaje como facilitadores de la construcción del conocimiento. Recuperado de: http://www.uoc.edu/symposia/spdece05/pdf/ID16.pdf

Dorado, D. J. (2006). Breve reflexión sobre entornos virtuales de aprendizaje. XIII Encuentro de la Escuela Regional de Matemáticas. Pereira: Universidad Tecnológica de Pereira.

Fleming, N. (2001). Encuesta para estilos de aprendizaje vark. Recuperado de http://www.vark-learn.com/english/index.asp

Galvis, A. (1997). Ingeniería del Software. Bogotá: Universidad de los Andes.

Gómez, F. (2004). Plataformas virtuales y diseño de cursos. Pontificia universidad Católica de Valparaíso. Recuperado de http://www.uvalpovirtual.cl/archivos/simposio2004/ Francisca\%20Gomez\%20\%20Plataformas\%20Virtuales\%20y\%20Di seno\%20de\%20Cursos.pdf

González, H. M. (2009). Modelo dinámico del estudiante en cursos virtuales adaptativos utilizando técnicas de inteligencia artificial. Recuperado de: 
http://www.bdigital.unal.edu.co/2317/1/75094455.20091.pdf

González, Myriam Cecilia Leguizamón. "Diseño y desarrollo de materiales educativos computarizados (MEC): una posibilidad para integrar la informática con las demás áreas del currículo." Revista UCN, 2006: 12.

Gros, B. (2002). Constructivismo y diseños de entornos virtuales de aprendizaje. Revista de Educación, 328, 225-247.

Gutiérrez, Héctor Mauricio González. Sinab - Sistema Nacional de Bibliotecas. 1 de 6 de 2009

http://www.bdigital.unal.edu.co/2317/1/75094455.20091.pdf (último acceso: 26 de 3 de 2014).

Instituto de Ingenieros Eléctricos y Electrónicos (IEEE). (2003). IEEE Learning Technology Standards Committee (LTSC). Recuperado de http://www.ieeeltsc.org:8080/Plone

Lozada, Vanessa. Japón - Harajuku: y el Mundo Occidental. Bogotá: Monreso, 2014.

Marqués, P. (2000). Los docentes: funciones, roles, competencias necesarias, formación. Recuperado de: http://www.cite.com.mx/documentos/antologia/iiid.pdf

Mora, Manuel Antonio Velandia. Estrategias para construir la convivencia solidaria en el aula universitaria . Bogotá: Universidad Cooperativa de Colombia., 2005.

Onrubia, J. (2003). Aprender y ensenar en entornos virtuales: Actividad conjunta, ayuda pedagógica y construcción del conocimiento. Barcelona: Universidad de Barcelona.

Onrubia, Javier. RED. Revista de Educación a Distancia. 20 de 2 de 2005. http://www.um.es/ead/red/M2/conferencia_onrubia.pdf (último acceso: 26 de 3 de 2014).

Osorio, M. (1999). El aprendizaje: Tematización obligatoria en la práctica educativa. Universidad del Norte. Recuperado de: http://www.uninorte.edu.co/divisiones/iese/lumen/ediciones/1 /articulo4.html

Quiceno, Jorge Obando y Mónica. Memoria Vol. 11 de num.19 de 2013. 12 de 06 de 2013.

http://revistas.ucc.edu.co/mdex.php/me/article/viewFile/117/ 118 (último acceso: 26 de 3 de 2014).

Quiroz, Juan Silva. Diseño y moderación de entornos virtuales de aprendizaje. Barcelona: UOC, 2011.

Salvat, Begoña Gros. "Constructivismo y diseños de entornos virtuales de aprendizaje." Revista de educación., 2002 : 225-247. 